Faculdade

de Ciências Econômicas UFRGS

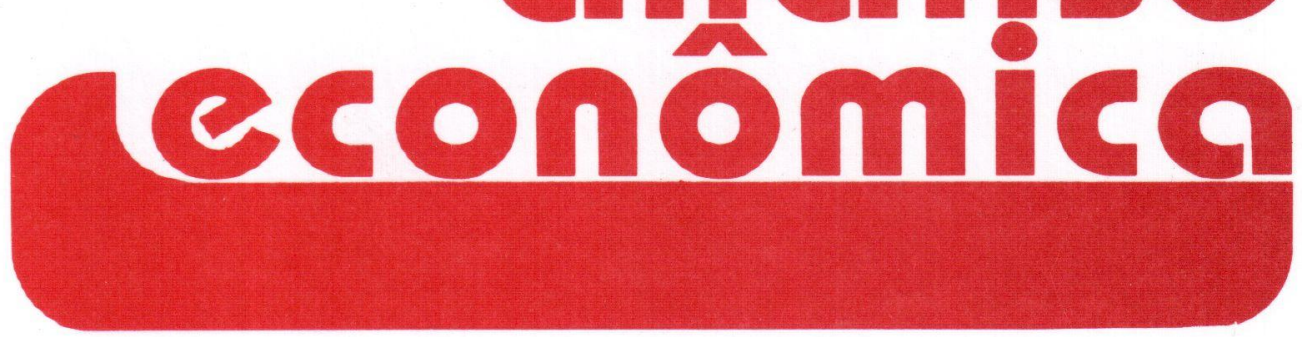

- UM SÉCULOdE INFLAÇÃO: A EVIDÊNCIA EMPÍRICA Fábio Sá Earp

- REGIÕES-CHAVENAINTEGRAÇÃo ECONÔMICA REGIONAL Nali de Jesus de Souza

- THESRAFFIAN INTERPRETATION OF RICARDO: ACRITIQUE José Ricardo Bezerra Nogueira

- QUALIDADE DO MEIO AMBIENTE EFALHAS DE MERCADO

Francisco de Sousa Ramos

- EFEITOS ECONÔMICOS DEESTRATÉGIAS DE PROMOÇÃODE EXPORTAÇÕES Wilson da Cruz Vieira

- "KEYNESIANS", MONETARISTS,NEW CLASSICALS AND NEW KEYNESIANS Fernando Ferrari Filho

- DISTRIBUIÇÃO DA RENDA DO TRABALHO NAINDÚSTRIA BRASILEIRA

Antonio Lisboa Teles da Rosa

- CURSO dE EXTENSÃO EM ECONOMIA PREPARATÓRIO PARA A ANPEC

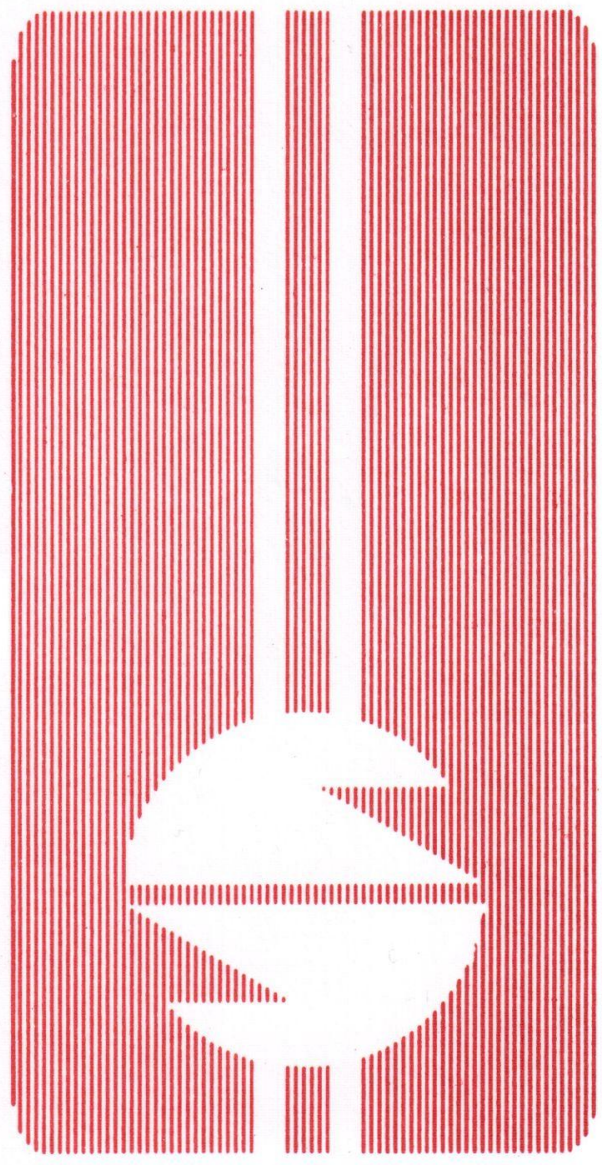


UNIVERSIDADE FEDERAL DO RIO GRANDE DO SUL

Reitor. Prof. Hélgio Henrique Casses Trindade

FACULDADE DE CIÊNCIAS ECONÔMICAS

Diretor. Prof. Pedro Cézar Dutra Fonseca

CENTRO DE ESTUDOS E PEQUISAS ECONÔMICAS

Diretor. Prof. Paulo Alexandre Spohr

DEPARTAMENTO DE CIÊNCIAS ECONÔMICAS

Chefe: Prof. Gentil Corazza

CURSO DE PÓS-GRADUAÇĀO EM ECONOMIA

Coordenador Prof Roberto Camps Moraes

CURSO DE PÓS-GRADUAÇÃO EM ECONOMIA RURAL

Coordenador. Prof. Aray Miguel Feldens

CONSELHO EDITORIAL: Achyles Barcelos da Costa, Aray Miguel Feldens, Atos Freitas Grawunder, Carlos Augusto Crusius, Eugenio Lagemann, Fernando Ferrari Filho, Gentil Corazza, Marcelo Savino Portugal, Maria Imilda da Costa e Silva, Nali de Jesus de Souza, Nuno R. L. de Figueiredo Pinto, Otília Beatriz K Carrion, Paulo Alexandre Spohr, Paulo Dabdab Waquil, Pedro Cezar Dutra Fonseca, Roberto Camps Moraes, Valter José Stulp, David Garlow (Wharton Econometrics Forecasts Association, E.U.A.), Edgar Augusto Lanzer (UFSC), Eleutério F. S. Prado (USP), Fernando de Holanda Barbosa (FGV/RJ), Gustavo Franco (PUC/RJ), JJoão Rogério Sanson (UFSC), Joaquim Pinto de Andrade (UnB), Juan H. Moldau (USP), Werner Baer (Univ de lllinois, E. U.A.).

COMISSÃO EDITORIAL: Fernando Ferrari Filho, Gentil Corazza, Paulo Dabdab Waquil, Marcelo Savino Portugal, Roberto Camps Moraes.

EDITOR: Nali de Jesus de Souza

SECRETARIA Cláudia Porto Silveira, Jeferson Luis Bittencourt e Vanete Ricachescki (revisão de textos).

FUNDADOR: Prof. Antônio Carlos Santos Rosa

Os materiais publicados na revista Análise Econômica são da exclusiva responsabilidade dos autores. É permitida a reprodução total ou parcial dos trabalhos, desde que seja citada a fonte.

Aceita-se permuta com revistas congêneres. Aceitam-se, também, livros para divulgação, elaboração de resenhas e recensões.

Toda correspondência, material para publicação (vide normas na terceira capa), assinaturas e permutas devem ser dirigidos ao seguinte destinatário:

PROF. NALI DE JESUS DE SOUZA

Revista Análise Econômica

Av. João Pessoa, 52

CEP 90040-000 PORTO ALEGRE - RS, BRASIL

Telefones: (051) 316-3348 e 316-3440

Fax: (051) 225-1067 


\section{UMA ANÁLISE DOS EFEITOS ECONÔMICOS DE ESTRATÉGIAS DE PROMOÇÃO DE EXPORTAÇÕES}

Wilson da Cruz Vieira"

\section{SINOPSE}

O principal objetivo deste trabalho foi o de analisar os efeitos econômicos de diferentes estratégias de promoção de exportações, associadas aos incentivos à exportação de produtos com maior ou menor valor adicionado. Consideraram-se oito setores da economia brasileira. Agricultura, Mineração, Minerais NãoMetálicos, Bens de Capital (Mecânica, Material Elétrico e Material de Transporte), Químico e Produtos Alimentares Simularam-se aumentos da demanda de exportaçäo destes setores a partir de uma versão agregada da matriz brasileira de insumo-produto, verificando seus efeitos sobre a produção setorial, utilização de insumos importados e absorção de mão-de-obra. O estímulo à exportação do setor Produtos Alimentares apresentou os melhores resultados, em termos dos parâmetros considerados, quando comparado aos outros setores analisados.

\section{INTRODUÇÃO}

As exportações brasileiras constituíram-se, por um longo período, principalmente de produtos agrícolas. A partir de meados da década de 60 , no entanto, há uma tendência da redução da participação relativa do setor agrícola no comércio exterior brasileiro Isto é atribuído como consequência do avanço do processo de industrialização e de uma série de incentivos que têm como objetivo promover as exportações de produtos manufaturados Estes incentivos, por outro lado, estimularam a exportação de produtos agrícolas transformados industrialmente, em detrimento de produtos in natura. Desta forma, óleo de soja, manteiga de cacau, café industrializado e suco de laranja, p ex., que tinham pequena participação nas exportações do País, representam atualmente parcela significativa.

Os incentivos às exportações, priorizando produtos com maior valor adicionado, diversificou a pauta de exportações do País. No entanto produtos com pouca ou nenhuma transformação como minério de ferro e produtos agrícolas in natura, provavelmente devido a vantagens comparativas e/ou preços externos favoráveis, têm contribuído ainda para o fortalecimento da balança comercial brasileira.

A política de promoção de exportações seguiu-se do esgotamento do modelo de substituição de importações e reflete uma preocupação constante do País em relação à escassez de divisas. Diversos instrumentos foram implementados para promover as exportações brasileiras de produtos manufaturados, sejam de natureza fiscal, monetária ou cambial. Medidas complementares como promoção comercial, investimentos em infra-estrutura, entre outras, também foram adotadas pelo

Este artigo foi apresentado no XXXIV Congresso Brasileiro de Economia e Sociologia Rural, em Aracaju SE, em agosto de 1996

Prof Adjunto do Departamento de Economia Rural / UFV. CEP 36571-000 - Viçosa - MG

Cod. AEA: 424 Palavras-chave: exportações, modelo de insumo-produto, uso de fatores.

\begin{tabular}{l|l|l|r|} 
ANÁLISE ECONÔMICA & ANO 14 & Março/Setembro 96 & p. 52-62
\end{tabular}


Governo brasileiro com o objetivo de promover as exportações de produtos manufaturados $^{1}$

Vários trabalhos procuraram avaliar a política de promoção de exportações. As abordagens procuram quantificar os incentivos dados às exportações [ver, por exemplo, Cardoso (1980)], aplicar a teoria da proteção efetiva à promoção das exportações [ver Pastore et alii (1979)] ou comparar o custo social da obtenção de divisas e a distribuição dos incentivos por setores. Estudos mais recentes têm procurado estimar equações de oferta e demanda das exportações de produtos manufaturados [ver, por exemplo, Braga \& Markwald (1983)]

No presente trabalho, procurou-se destacar as relações intersetoriais da economia brasileira comparando diferentes estratégias de promoção de exportações, associadas aos incentivos à exportação de produtos com maior ou menor valor adicionado A política de promoção de exportações pós-1964 beneficiou de forma explícita produtos manufaturados. Entretanto, com este tipo de política, pode-se estar deixando de aproveitar vantagens comparativas de setores cujos produtos apresentem menor valor adicionado, ou mesmo no caso de setores cujos produtos possuem maior valor adicionado, este tipo de politica pode não ser interessante no sentido da geração de divisas, pois o estímulo à exportação de produtos destes setores pode aumentar de forma significativa a demanda por insumos importados. Na comparação das diferentes estratégias de promoção de exportações utilizou-se como parâmetros os efeitos destas estratégias sobre a produção setorial, uso de insumos importados e absorção de mão-de-obra Selecionou-se setores cujos produtos apresentam maior ou menor valor adicionado, segundo sua importância na pauta de exportações, e efetuou-se simulações do aumento de suas demandas de exportação $O$ modelo de insumo-produto de Leontief foi utilizado como instrumento analítico

$\mathrm{Na}$ seção seguinte, apresenta-se a método empregado neste trabalho, com indicação dos dados utilizados, modelo analitico e simulações efetuadas. Os resultados obtidos e discussão estão na seção 3. Finalmente, na seção 4 , apresentam-se as principais conclusões.

\section{MÉTODO}

\subsection{Dados}

Os dados utilizados neste trabalho foram obtidos da matriz brasileira de insumo-produto de 1980 (IBGE, 1989). As duas primeiras tabelas do IBGE [IBGE, 1989, p. 50-70; tabela 1 - Produção e tabela 2 - Insumo das Atividades e Demanda Final] foram agregadas conforme indicado no Quadro 1

Este padrão de agregação é semelhante ao utilizado por Fonseca \& Guilhoto (1987). Estes autores, ao analisarem os efeitos econômicos de estratégias setoriais, agregarem a matriz brasileira de insumo-produto de 1975 em 27 setores. Neste trabalho, agregou-se a matriz de insumo-produto de 1980 em 25 setores. O padrão de agregação selecionado, além de facilitar a manipulação dos dados, deve levar em conta o(s) objetivo(s) a que se propōe(m)

\footnotetext{
1 Para maiores detalhes sobre os instrumentos e medidas adotadas pelo Governo brasileiro para promover as exportações de produtos manufaturados pós-1964, o leitor pode consultar, por exemplo, Santos (1980) ou Menezes (1988)
} 
Quadro 1 - Agregação de setores e produtos da matriz brasileira de nsumo-produto 1980

\begin{tabular}{|c|c|}
\hline Setores e Codificação & Codificação dos Produtos \\
\hline 01 Agricultura $0100^{1}$ & 01001 a $01017^{1}$ \\
\hline 02. Mineração 0210 & 02101 a 02102 \\
\hline 03. Minerais Não-Metálicos 0220 a 0440 & 02201 a 04401 \\
\hline 04. Metalurgia 0510 a 0720 & 05101 a 07202 \\
\hline 05 Mecânica 0810 a 0910 & 08101 a 09101 \\
\hline 06. Material Elétrico 1010 a 1120 & 10101 a 11201 \\
\hline 07. Material de Transporte 1210 a 1340 & 12101 a 13401 \\
\hline 08. Madeira e Mobiliário 1410 a 1420 & 14101 a 14201 \\
\hline 09. Papel e Papelão 1510 a 1520 & 15101 a 15201 \\
\hline 10. Editorial e Gráfica 1530 & 15301 a 15302 \\
\hline 11. Borracha 1610 & 16101 a 16102 \\
\hline 12. Química 1710 a 1920 & 17101 a 19202 \\
\hline 13. Farmacêutica 2010 & 20101 a 20102 \\
\hline 14. Perfumaria 2020 & 20201 \\
\hline 15 Plásticos 2110 a 2120 & 21101 a 21201 \\
\hline 16. Têxtil 2210 a 2230 & 22101 a 22301 \\
\hline 17. Vestuário, Couro e Calçados 2310 a 2420 & 23101 a 24201 \\
\hline 18 Produtos Alimentares 2510 a $3120(-2650)^{2}$ & 25101 a $31201(26501)^{2}$ \\
\hline 19. Fumo 2650 & 26501 \\
\hline 20. Bebidas 3130 & 31301 \\
\hline 21. Diversos $3210(+4410)^{3}$ & 32101 a 32903 \\
\hline 22. Energia, Água e Saneamento 3310 a 3320 & 33101 a 33201 \\
\hline 23. Construção Civil 3410 & 34101 \\
\hline $\begin{array}{l}\text { 24. Transporte e Margem Comércio } 3510 \text { a } 3640 \\
25 \text { Servicos } 3710 \text { a } 4310(+4510)^{4}\end{array}$ & $\begin{array}{c}35101 \text { a } 36401 \\
37101 \text { a } 43102(+45101)^{4}\end{array}$ \\
\hline
\end{tabular}

Fonte: IBGE (1989) - Agregaçốes feitas pelo autor

Notas:1. Codificaçäo utilizada pelo IBGE, 2 Excetuam-se o setor fumo e seu produto;

3 Incluiu-se neste setor a dummy reparação; 4 . Incluiu-se neste setor a dummy empresas

$\mathrm{O}$ padrão de agregação indicado no Quadro 1 permite definir as matrizes $V$ (setores $x$ produtos) e $U$ (produtos $x$ setores) com as dimensões $25 \times 25$. Estas matrizes, obtidas, respectivamente, das primeira e segunda tabelas do IBGE [IBGE (1989) p 50-70] serão importantes na formulação do sistema básico de equações de Leontief, que será discutido na seção seguinte.

\subsection{Modelo analítico}

O modelo de insumo-produto de Leontief é uma adaptação da teoria neoclássica de equilibrio geral para o estudo empírico das inter-relações entre os vários setores de uma economia Uma das hipóteses básicas do modelo é que os insumos são utilizados em proporções fixas. Na modelagem de insumo-produto, as demandas são conhecidas e fixas; as variáveis relevantes são as quantidades totais dos bens demandados ou ofertados (Leontief, 1965).

Os fluxos intersetoriais de bens e serviços de uma economia, determinados por fatores tecnológicos e econômicos, podem ser descritos por um sistema de equações simultâneas da seguinte forma (Leontief, 1965)

$$
x=A x+D
$$

onde:

$x=$ vetor $(n \times 1)$ com o produto total de cada setor,

$d=$ vetor $(n \times 1)$ com a demanda final setorial; e 
$A=$ matriz (nxn) corn os coeficientes técnicos de produção.

Neste modelo, com o vetor de demanda final setorial conhecido e fixo, pode-se determinar o vetor de produto total setorial através da seguinte equação matricial:

$$
x=(l-A)^{-1} d
$$

Este modelo básico de Leontief é classificado como de tecnologia baseada na indústria e com enfoque indústria $x$ indústria $\dot{E}$ importante ressaltar que as tabelas da matriz brasileira de insumo-produto permitem a utilização de outros enfoques como, por exemplo, indústria $x$ produto, produto $x$ produto Neste trabalho, optou-se por trabalhar com 0 enfoque indústria $x$ indústria por ser 0 mais comumente utilidado A matriz dos coeficientes técnicos de produção (matriz $A$ do modelo de Leontief) pode ser obtida indiretamente das tabelas da matriz brasileira de insumoproduto Esta matriz, neste trabalho, foi gerada a partir das matrizes $\mathrm{V}$ e $\mathrm{U}$, obtidas das agregações explicitadas acima. Procedeu-se da seguinte forma: Inicialmente definiu-se a seguinte matriz de coeficientes técnicos

$$
B=U(\hat{x})^{-1}
$$

$\hat{n}$

onde $\mathrm{X}$ é o vetor $x$ diagonalizado

Das tabelas da matriz brasileira de insumo-produto pode-se obter ainda os vetores agregados $E(25 \times 1)$ (total da demanda final) e $\mathrm{Q}(25 \times 1)$ (total da demanda: $Q=U+E)$ [IBGE (1989) p.70] $]^{2}$. Definiu-se, então, a matriz D $(25 \times 25)$, cujos elementos medem a fração da produção total do bem "j" produzido pelo setor "i" da seguinte forma:

$$
D=V(\hat{Q})^{-1}
$$

$\hat{Q}$

onde $Q$ é o vetor $Q$ diagonalizado

Os fluxos intersetorias podem ser expressos na forma

$Q=B x+E$

Desde que $U=B x$. Sabendo-se que: $x=V=D Q$, obtém-se: ${ }^{3}$

$Q=B D Q+E$

Executando operações matriciais relevantes, obtém-se

$Q=(I-B D)^{-1} E$

Note-se que: $d=D E$ Esta relação transforma a demanda final por produto em demanda final setorial Novamente fazendo as operações matriciais relevantes, obtém-se a equação matricial final:

$$
x=(1-D B)^{-1} d
$$

onde DB é a matriz dos coeficientes técnicos de produção.

\footnotetext{
2 Deve ser entendido como a soma das colunas da matriz $U$ mais a coluna do vetor $E$, o que é igual ao vetor $Q$ (identidade contábil) Não confundir como a soma de uma matriz (U) com um vetor (E), o que seria uma operação matricial impossivel de ser feita

${ }^{3}$ Novamente deve ser entendido como a soma das colunas da matriz $\vee$ é igual ao vetor $x$ (identidade contábil)
} 


\subsection{Simulações}

Selecionou-se oito setores da economia brasileira para fazer as simulações do aumento da demanda de exportações. Estes setores são: Agricultura, Mineração, Minerais Não-Metálicos, Bens de Capital (Mecânica, Material Elétrico e Material de Transporte), Químico e Produtos Alimentares

Simularam-se aumentos da demanda de exportação de cada setor de Cr\$ $30.000,00$ milhões de cruzeiros ${ }^{4}$ No caso do setor de bens de capital, subdividiu-se este valor (iguaimente) para os setores de Mecânica, Material elétrico e Material de transporte. Este aumento simulado das exportações foi maior no setor Minerais Não-Metálicos (171,49\%) e menor no setor Produtos Alimentares (10,63\%), quando comparados aos valores efetivamente exportados em 1980 (IBGE, 1989).

Estas simulações foram feitas da seguinte forma a) subdividiu-se o vetor $d$ (demanda final setorial) nos vetores $(d-e x)$ e "ex", onde este ultimo é o vetor $(25 \times 1)$ do total das exportações setoriais; b) adicionou-se o aumento simulado das exportações dos respectivos setores ao vetor $d \cdot d=(d-$ ex $)+$ ex Observe-se que o vetor ex é obtido de forma semelhante ao vetor $d$ e foi separado deste último para facilitar a adição do valor simulado de cada estratégia considerada.

\section{RESULTADOS E DISCUSSÃO}

$\mathrm{Na}$ Tabela $1 \mathrm{~A}$ (em apêndice) apresenta-se a matriz de coeficientes técnicos de produção DB $(25 \times 25)$. Os resultados dos efeitos das estratégias de promoção de exportações sobre a produção setorial são mostrados na Tabela 1 . As colunas $\Delta e x$ indicam os acréscimos na demanda final exógena (exportações) e as colunas $\Delta x$ mostram os impactos na produção setorial dos fluxos intersetoriais $A$ seguir são feitas comparações dos resultados para as diferentes estratégias de promoção de exportações (setores cujos produtos apresentam menor ou maior valor adicionado)

a) Estratégias 1 e 6: aumento das exportações da Agricultura e de Produtos Alimentares, respectivamente. Comparando-se essas estratégias, verifica-se que as maiores alterações relativas da estratégia 1 na produção setorial são observadas nos setores: 1 (Agricultura) e 12 (Químico) A estratégia 6 apresentou variação na produção total superior em todos os demais setores Esta, em termos da produção total agregada, causou mais impacto relativo do as demais

b) Estratégias 2 e 4 : aumento das exportações dos setores de Mineração e Bens de Capital, respectivamente Comparando-se estas estratégias nota-se que a 2 apresentou maior variação relativa na produção total nos setores: 2 (Mineração), 3 (Minerais Não-Metálicos), 22 (Energia, Agua e Saneamento), 23 (Construção Civil), 24 (Transporte e Margem do Comércio) e 25 (Serviços). Em termos agregados, a maior variação na produção total foi observada na estratégia 4

c) Estratégias 3 e 5 aumento das exportações dos setores de Minerais Não-Metálicos e Químico, respectivamente A estratégia 3, comparativamente à 5,

\footnotetext{
${ }^{4}$ Estes valores correspondem a cruzeiros de 1980
} 
Tabela 1 - Efeitos de diferentes estratégias de promoção de exportações na produção intersetorial (variação em milhões de Cr\$ de 1980)

\begin{tabular}{|c|c|c|c|c|c|c|c|c|c|c|c|c|}
\hline \multirow{3}{*}{ Setores } & \multicolumn{12}{|c|}{ Estratégia } \\
\hline & \multicolumn{2}{|r|}{1} & \multicolumn{2}{|r|}{2} & \multicolumn{2}{|r|}{3} & \multicolumn{2}{|r|}{4} & \multicolumn{2}{|r|}{5} & \multicolumn{2}{|r|}{6} \\
\hline & $\Delta \mathrm{ex}$ & $\Delta x$ & $\Delta \mathrm{ex}$ & $\Delta x$ & $\Delta \mathrm{ex}$ & $\Delta x$ & $\Delta \mathrm{ex}$ & $\Delta x$ & $\Delta \mathrm{ex}$ & $\Delta x$ & $\Delta e x$ & $\Delta x$ \\
\hline 1 Agricultura & 30000 & 3629347 & - & 27628 & - & 58233 & - & 55250 & - & 1133.39 & $\cdot$ & 19218.02 \\
\hline 2 Miner & - & 20.56 & 30000 & 3218633 & - & 101.29 & - & 369.66 & - & 8297 & - & 5898 \\
\hline 3. Min N & - & 284.45 & - & 836.40 & 30000 & 3640453 & - & 82065 & - & 1478.22 & - & 425.21 \\
\hline 4. Metalurgia & - & 46585 & - & 1511.32 & - & 226683 & - & 1159140 & - & 1264.31 & - & 167498 \\
\hline 5 Mecârica & - & 262.26 & - & 207817 & - & 1781.72 & 10000 & 1328597 & - & 81144 & - & 70567 \\
\hline 6. Mat $\mathrm{E}$ & - & 39.33 & - & 16278 & - & 19322 & 10000 & 12508.74 & - & 10155 & - & 9368 \\
\hline $7 \mathrm{Ma}$ & - & 222 & - & 251.01 & - & 26786 & 10000 & 1398562 & - & 20856 & - & 226.45 \\
\hline $8 M$ & - & 84 & - & 95 & - & 13535 & - & 50049 & - & 90.04 & - & 104.11 \\
\hline$P$ & - & 144.29 & - & 14339 & - & 80026 & . & 380.16 & - & 28789 & - & 75685 \\
\hline $10 E$ & - & 47.14 & - & 10954 & - & 139.14 & - & 147.80 & - & 78.46 & - & 13726 \\
\hline $11 \mathrm{E}$ & - & 6074 & - & 132.51 & - & 140.35 & - & 81042 & - & 10902 & - & 112.87 \\
\hline $12 Q$ & - & 465708 & - & 2051.15 & - & 3653.17 & . & 2231.15 & 30000 & 3696193 & - & 375645 \\
\hline êutica & - & 125.20 & - & 3160 & - & 3602 & - & 3646 & - & 4181 & - & 17020 \\
\hline $14 \mathrm{P}$ & $\cdot$ & 776 & - & 764 & - & 1039 & - & 1006 & - & 1520 & - & 10.78 \\
\hline $15 \mathrm{P}$ & - & 15320 & - & 92.42 & - & 17678 & - & 66638 & - & 19672 & - & 42458 \\
\hline $16 \mathrm{~T}$ & - & 244.17 & - & 19620 & - & 290.57 & - & 451.12 & - & 20614 & - & 76142 \\
\hline $\begin{array}{l}\text { 17. Vest./ Couro/ } \\
\text { Calçados }\end{array}$ & - & 23.80 & - & 2370 & - & 34.06 & - & 89.10 & $\cdot$ & 38.53 & - & 47.35 \\
\hline $18 \mathrm{Pr}$ & - & 272063 & - & 214.20 & - & 277.18 & - & 286.09 & - & 70463 & 30000 & 3762520 \\
\hline 19. F & - & 0.40 & - & 182 & - & 1.93 & - & 10.08 & - & 1.43 & - & $1.0 \uparrow$ \\
\hline 20.8 & - & 17.77 & - & $\begin{array}{ll}41 & 29\end{array}$ & - & 4190 & - & 4214 & - & 40.13 & - & 41.10 \\
\hline $21 \mathrm{D}$ & - & 1145 세 & - & 486.15 & - & 568.03 & - & 102521 & - & 47663 & - & 29477 \\
\hline $\begin{array}{l}\text { 22. Enc/ / Águal } \\
\text { Sanemento }\end{array}$ & - & 264.14 & - & 89592 & - & 1158.20 & - & 701.74 & - & 570.47 & - & 601.48 \\
\hline 23. Const Civil & - & 65.01 & - & 174.40 & - & 17245 & - & 16964 & - & 103.71 & - & 14479 \\
\hline $\begin{array}{l}24 \text { Transp/Marg } \\
\text { Comércio }\end{array}$ & - & 324468 & - & 2822.92 & - & 3054.97 & - & 249908 & - & 334669 & - & 454109 \\
\hline 25.Serviços & - & 1796.40 & $\because$ & 5889.07 & - & 5706.87 & $\therefore$ & 5813.89 & - & 3211.73 & - & 4532.74 \\
\hline Total & 30000 & 51232.93 & 30000 & 50714.15 & 30000 & $57995.39 / 3$ & 30000 & $68985.55 \mid 3$ & 30000 & 51561.603 & 30000 & 76467.05 \\
\hline
\end{tabular}

Fonte: Estimativas feitas pelo autor.

Notas: ৯ex - Acréscimo na demanda final exógena (exportação); $\Delta x$ - Efeitos intersetoriais

mostra variação relativa na produção total superior na maioria dos setores, excetuando-se: 1 (Agricultura), 12 (Quimico), 13 (Farmacêutica), 14 (Perfumaria), 15 (Plásticos), 17 (Vestuário, Couro e Calçados), 18 (Produtos Alimentares) e 24 (Transporte e Margem do Comércio) A variação da produção total agregada foi maior relativamente na estratégia 3 do que na estratégia 5.

$\mathrm{Na} \mathrm{Tab} 2$, mostram-se os aumentos no uso de insumos importados resultante de cada estratégia. Estes dados foram obtidos multiplicando-se um vetor de coeficientes de insumos importados pelas colunas $\Delta \mathrm{x}$ da Tab 1 . Os resultados mostram que as maiores importações de insumos estão relacionadas à estratégia 5 e as menores importações à estratégia 2 Na Tabela 3 , mostram-se os aumentos na absorção de mão-de-obra resultante de cada estratégia Como no caso da utilização de insumos importados, estes dados foram obtidos multiplicando-se um vetor de coeficientes de uso de mão-de-obra ${ }^{5}$ pelas colunas $\Delta x$ da Tab. 1 . Os resultados mostram que a maior absorção de mão-de-obra está relacionada à estratégia 1 (Agricultura) e a menor absorção, à estratégia 5 (Químico).

\footnotetext{
${ }^{5}$ Os coeficientes de mão-de-obra foram obtidos a partir da tabela 12 do IBGE (IBGE, 1989, p 143-144), através da divisão do emprego no setor pelo respectivo valor da produção
} 
Calculou-se 0 índice de Rasmussem de ligações para frente e para trás dos oito setores analisados (Bulmer-Thomas, 1982). Estes índices, mostrados na Tabela 4, foram obtidos a partir das seguintes fórmulas:

índices de ligação para frente $\left(T_{i}\right)$ e para trás $\left(T_{j}\right)$, respectivamente:

$$
\begin{aligned}
& T_{i}=\left(\sum_{j=1}^{n} r_{i j} / n\right) /\left(\sum_{i=1}^{n} \sum_{j=1}^{n} r_{i j} / n \times n\right) \\
& T_{j}=\left(\sum_{j=1}^{n} r_{i j} / n\right) /\left(\sum_{i=1}^{n} \sum_{j=1}^{n} r_{i j} / n \times n\right)
\end{aligned}
$$

onde $r_{i j}$ é um elemento da matriz $(I-D B)^{-1}$.

Tabela 2 - Efeitos de diferentes estratégias de promoção de

\begin{tabular}{|c|c|c|c|c|c|c|}
\hline \multirow[t]{2}{*}{ Setores } & \multicolumn{6}{|c|}{ Estratédias } \\
\hline & 1 & 2 & 3 & 4 & 5 & 6 \\
\hline 1. Agricultura & 5727 & 0.44 & 092 & 0.87 & 1.79 & 30.33 \\
\hline 2. Mineraçäo & 016 & 252.35 & 079 & 2.90 & 0.65 & 046 \\
\hline 3. Minerais N-Met. & 275 & 8.09 & 352.16 & 7.94 & 14.30 & 411 \\
\hline 4 Metalurgia & 2425 & 7867 & 118.00 & 60339 & 6581 & 8719 \\
\hline 5. Mecânica & 918 & 72.73 & 62.36 & 464.98 & 28.40 & 2470 \\
\hline $6 \mathrm{Mat}$ Elètrico & 335 & 1386 & 1645 & 106478 & 864 & 7.97 \\
\hline 7 Mat Transp. & 5.27 & 1082 & 1154 & 60272 & 899 & 9.76 \\
\hline 8 Madeira/Mob & 0.32 & 054 & 074 & 274 & 049 & 0.57 \\
\hline 9.Papel/Papelão & 1.80 & 1.79 & 10.01 & 475 & 360 & 9.46 \\
\hline 10. Edit/Graf & 2.32 & 539 & 6.85 & 727 & 386 & 6.75 \\
\hline 11. Borracha & 4. 15 & 906 & 960 & 5543 & 746 & 772 \\
\hline 12. Químico & 177876 & 78343 & 139532 & 85218 & 1411752 & 1434.77 \\
\hline 13. Farmacêutica & 14.48 & 365 & 417 & 4.22 & 484 & 19.69 \\
\hline 14. Perfumaria & 0.46 & 0.45 & 062 & 0.60 & 0.90 & 0.64 \\
\hline 15 Plásticos & 442 & 267 & 510 & 19.24 & 568 & 1226 \\
\hline 16 Têxtil & 167 & 134 & 199 & 309 & 141 & 521 \\
\hline 17 Vest/Couro/Calç & 0.10 & 0.10 & 015 & 0.39 & 0.17 & 0.21 \\
\hline 18 Prod Aliment & 12955 & 1020 & 1320 & 13.62 & 3355 & 1791.56 \\
\hline 19. Fumo & 0.00 & 0.01 & 0.01 & 0.05 & 001 & 0.01 \\
\hline 20 Bebidas & 0.95 & 222 & 225 & 226 & 2. 15 & 221 \\
\hline 21. Diversos & 12.97 & 55.06 & 64.33 & 116.10 & 5398 & 33.38 \\
\hline 22 En/Ägua/Sanem & 1.01 & 341 & 441 & 267 & 217 & 229 \\
\hline 23 Const Civil & 0.89 & 2.38 & 235 & 2.31 & 141 & 197 \\
\hline 24 Transp/M Com & 14306 & 12446 & 13469 & 11019 & 14756 & 20022 \\
\hline 25 Serviços & 2869 & 94.06 & 9115 & 92.85 & 5130 & 7239 \\
\hline Total & 2227.84 & 1537.18 & 2309.15 & 4037.55 & 14566.64 & 3765.83 \\
\hline
\end{tabular}
exportaçōes nos insumos importados (variação em milhões de Cr\$ de 1980)

O índice de Rasmussem, assim como outros índices que medem ligações intersetoriais para frente e/ou para trás, permite identificar setores importantes de uma economia, ou seja, aqueles com indices relativamente altos de ligação para frente e para trás. Na Tabela 4 observa-se que os setores com maior e menor indice de ligação para trás são, respectivamente, os setores Material de Transporte e Mineração Os setores com maior e menor índice de ligação para frente são, respectivamente, o Químico e Mineração O setor Mineração apresentou os menores índices de ligação, tanto para frente como para trás. 
Tabela 3 - Efeitos de diferentes estratégias de promoção de exportações na absorção de mão-de-obra (geração de emprego)

\begin{tabular}{|c|c|c|c|c|c|c|}
\hline \multirow[t]{2}{*}{ Setores } & \multicolumn{6}{|c|}{ Estratécia } \\
\hline & 1 & 2 & 3 & 4 & 5 & 6 \\
\hline 1. Aaricultura & 290992.91 & 221513 & 466899 & 4429.81 & 9087.27 & 15408578 \\
\hline 2. Mineraçáo & 1717 & 2688575 & 8461 & 308.79 & 6930 & 49.27 \\
\hline 3 Minerais Não-Met & 35284 & 1037.49 & 45157.07 & 1017.95 & 1833.62 & $527 . .44$ \\
\hline 4 Metalurgia & 22224 & 720.98 & 108140 & 5529.73 & 603.15 & 79906 \\
\hline 5. Mecânica & 23078 & 182878 & 156790 & 11691.58 & 71406 & 620.99 \\
\hline 6 Mat Elétrico & 21.75 & 90.02 & 10686 & 691786 & 56.16 & 51.81 \\
\hline 7 Mat. Transp. & 6329 & 12998 & 138.71 & 7242.25 & 10800 & 117.26 \\
\hline 8 Madeira/Mob & 9436 & 15978 & 22079 & 81643 & 14688 & 16983 \\
\hline 9 Papel/Papelão & 7613 & 75.66 & 42226 & 200.59 & 151.91 & 39935 \\
\hline 10 Edit /Gráfica & 63.32 & 147.16 & 18692 & 19855 & 10541 & 184.39 \\
\hline 11 Borracha & 28.68 & 6256 & 6626 & 382.60 & 5147 & 53.29 \\
\hline 12. Quimico & 62042 & 273.26 & 48668 & 297.24 & 492411 & 50044 \\
\hline 13 Farmacêutica & 72.79 & 18.37 & 2094 & 2120 & 24.31 & 98.96 \\
\hline 14 Perfumaria & 3.33 & 3.28 & 446 & 432 & 653 & 463 \\
\hline 15 Plásticos & 10979 & 6623 & 126.68 & 477.55 & 140.98 & 30427 \\
\hline 16 Têxtil & 169.70 & 136.35 & 20194 & 313.52 & 14327 & 529.17 \\
\hline 17 Vest/Couro/Cal & 31.48 & 31.34 & 45.05 & 117.84 & 5096 & 62.63 \\
\hline 18 Prod Aliment. & 1221.92 & 9620 & 124.49 & 128.49 & 316.47 & 1689858 \\
\hline 19. Fumo & 019 & 0.88 & 0.94 & 4.88 & 0.69 & 049 \\
\hline 20. Bebidas & 1334 & 31.00 & 3146 & 3164 & 3013 & 30.86 \\
\hline 21 Diversos & 65.49 & 277.94 & 32475 & 58614 & 27250 & 16853 \\
\hline 22.. En/Água/Sanem & 186.69 & 63323 & 81861 & 495.98 & 403.20 & 42513 \\
\hline 23 Const Civil & 10935 & 29336 & 29008 & 285.34 & 174.44 & 243.54 \\
\hline 24. Transp/M Com. & 576661 & 501705 & 542945 & 444150 & 594792 & 807067 \\
\hline 25. Serviços & 411546 & 13491.54 & 13074.11 & 13319.29 & 7357.89 & 1038425 \\
\hline Total & 304650.03 & 53723.33 & 74681.41 & 59261.09 & 32720.61 & 194780.60 \\
\hline
\end{tabular}

Fonte: Estimativas feitas pelo autor

Tabela 4 - Indices de Rasmussen de ligação para frente e para trás de 8 setores da economia brasileira1980

\begin{tabular}{l|c|c}
\hline \multicolumn{1}{c|}{ Setores } & Ligação para frente & Ligação para trás \\
\hline 1. Agricultura & 1,5187 & 0,8156 \\
2. Mineração & 0,5850 & 0,8073 \\
3. Minerais Não-Metálicos & 0,9279 & 0,9232 \\
5. Mecânica & 1,0214 & 1,0604 \\
6. Material Elétrico & 0,6850 & 1,0004 \\
7. Material de Transporte & 0,7790 & 1,2338 \\
12. Químico & 2,1132 & 0,8208 \\
18.Produtos Alimentares & 0,9224 & 1,2173 \\
\hline
\end{tabular}

Fonte Estimativas feitas pelo autor.

\section{CONCLUSÕES}

Simularam-se diferentes estratégias de promoção de exportações, considerando-se setores cujos produtos apresentam maior ou menor valor adicionado. Os resultados obtidos mostram diferentes impactos das diversas estratégias na produção total setorial, utilização de insumos importados e absorção de mão-de-obra De modo geral, o aumento das exportações dos produtos com maior valor adicionado causam maior impacto no aumento da produção total setorial agregada. Das simulações efetuadas, apenas nos setores Minerais Não-Metálicos (menor valor adicionado) e Químico (maior valor adicionado) observou-se o contrário, mas por diferença pequena.

Em ordem decrescente, as estratégias de promoção de exportações que causaram maior impacto na produção setorial agregada foram Produtos 
Alimentares, Bens de Capital (Mecânica, Material Elétrico e Material de Transporte), Minerais Não-Metálicos, Químico, Agricultura e Mineração O setor Produtos Alimentares apresentou os efeitos mais favoráveis na produção total agregada com o aumento de suas exportações.

No caso da utilização de insumos importados, o setor Químico contribuiu com o maior volume de importações com o aumento de suas exportações. O setor Mineração é o que menos importa insumos com o aumento de suas exportações. Os outros setores que mais importaram insumos com o aumento de suas exportações foram (em ordem decrescente): Bens de Capital, Produtos Alimentares, Minerais Não-Metálicos e Agricultura. Estes setores importam relativamente pouco quando comparados ao setor Químico.

No caso do uso de mão-de-obra, o setor Agricultura contribuiu com a maior absorção deste fator de produção com o aumento de suas exportações O setor Químico é o que menos absorve mão-de-obra com o aumento de suas exportações. Os outros setores que mais absorveram mão-de-obra com o aumento de suas exportações foram (em ordem decrescente): Produtos Alimentares, Minerais NãoMetálicos, Bens de Capital e Mineração

O cálculo dos índices de ligação para frente e para trás da economia brasileira (1980) (índice de Rasmussen) para os sefores analisados mostrou o setor Químico como o setor com maior indice de ligação para frente e o setor Material de Transporte como o setor com maior índice de ligação para trás $O$ setor Produtos Alimentares apresentou índices de ligação relativamente altos, tanto para frente como para trás. Já o setor Mineração apresentou os menores índices de ligação, tanto para frente como para trás

\section{BIBLIOGRAFIA}

BRAGA, H C. \& MARKWALD, R A Funções de oferta e demanda das exportaçoes de manufaturados no Brasil estimaçäo de um modelo simultâneo Pesquisa e Planej Econômico, v 13, n 3, p 707-743, 1983

BULMER-THOMAS, V Input-output analysis in developing countries. N York. J.Wiley, 1982, 297 p

CARDOSO, E Incentivos às exportações de manufaturados série histórica Revista Brasileira de Economia. $\vee 34, \mathrm{n} 2, \mathrm{p} 241-250,1980$

FONSECA, M. A R da \& GUILHOTO, J J M Uma análise dos efeitos econômicos de estratégias setoriais. Revista Brasileira de Economia v 41, n 1, p 81-98, 1987

FUNDAÇÄO INSTITUTO BRASILEIRO DE GEOGRAFIA E ESTATISTICA-IBGE. Matriz de insumo-produto. Brasil - 1980. Rio de Janeiro, 1989 v.7, 203p (Série relatórios metodológicos).

LEONTIEF, W. Input-output economics New York, Oxford University Press, 1966, 257p

MENEZES, F M A estratégia comercial brasileira- 1965/1985 R Janeiro. FGV, 1988 174p (Diss Mestrado)

PASTORE, A C et alii. Quantificação dos incentivos às exportações Rio de Janeiro, Fundação Centro de Estudos do Comércio Exterior, 1979

SANTOS, M L de M A politica de promoção de exportações e os seus reflexos sobre o setor agricola Viçosa, UFV, 1980. 101p (Diss Mestrado).

\section{ABSTRACT - AN ANALYSIS OF THE ECONOMIC EFFECTS OF EXPORTS PROMOTION STRATEGIES}

The main purpose of this paper is to study the economic effects of different strategies for the promotion of exports, associated with export incentives of high and small added value goods Eight sectors of the Brazilian economy were considered in the study. agriculture, mining, non-metalic minerals, capital goods (including mechanics, eletric and transportation materials), chemicals, and processed food products. Increases in export demand for these sectors were simulated through an aggregated version of the Inputoutput Brazilian matrix. The estimated economic effects were the changes in output, imported inputs, and in employment The findings of this study indicate that the processed food sector is likely to show the best economic performance 


\section{APÊNDICE}

Tabela 1A - Matriz de coeficientes técnicos - 1980 (Matriz DB)

\begin{tabular}{|c|c|c|c|c|c|c|c|c|c|c|}
\hline & 1 & 2 & 3 & 4 & 5 & 6 & 7 & 8 & 9 & 10 \\
\hline 1 Agricultura & 0.13742 & 000053 & 0.00546 & 01309 & 00016 & 00011 & 0.00032 & 0.09773 & 0.02232 & 000007 \\
\hline & & 6641 & 063 & & & & 0.00030 & 000006 & 0.00054 & 0.0001 \\
\hline & & 669 & 6968 & 001505 & 000673 & & 0.00730 & & 000657 & 00004 \\
\hline & & 810 & 1998 & 042040 & 0. 19669 & & & & 01238 & \\
\hline & & 018 & 3560 & 003864 & 0.12466 & & 3847 & 133 & 02684 & \\
\hline & & & 0138 & 000319 & 698 & & & & 118 & 006 \\
\hline & 222 & 18 & 000125 & 0.00535 & & & 601 & & 257 & 81 \\
\hline & & & 0.00150 & 0.00303 & & & 074 & & 311 & \\
\hline & & $\sigma 00024$ & & 271 & & & & & 82 & \\
\hline 0 & & 000003 & 0.0 & & & & & & 80 & \\
\hline $1 \mathrm{E}$ & & & 023 & & & & & & 076 & \\
\hline & 092246 & & & & & & & 189 & 7350 & \\
\hline Atica & 727 & & & & & & 013 & & 0032 & \\
\hline $4 P$ & & & & & & & 006 & & 018 & \\
\hline 5 & 73 & & & 221 & & & & & 9419 & \\
\hline & & & 240 & & & & & & 479 & \\
\hline 1 & & & & 00 & & & 242 & & & \\
\hline & & & & 0.00130 & 0.00059 & & 270 & & & \\
\hline & & & 000001 & 000003 & 000 & & & & & \\
\hline & & 0.00005 & 0.00006 & 0.00007 & 0.0 & & & & 910 & \\
\hline & 0.00049 & 0.01016 & 0.01020 & 002199 & 002 & & & & 2133 & 000651 \\
\hline 2. Er & 0002273 & 001617 & 0.01899 & 001537 & 000715 & 0.00355 & 0.00472 & 001017 & 0.02175 & 000510 \\
\hline- & 0000035 & & 0 & & & & & 0 & & \\
\hline -7. & 0.062342 & 0.05 & & & & & & & & \\
\hline $0.5 \mathrm{e}$ & .01835 & 0.12708 & 0.10365 & 0.05863 & 0.09303 & 0.08561 & 0.07956 & 0.09280 & 0.08269 & 0.15725 \\
\hline
\end{tabular}

Tabela $1 \mathrm{~A}$ (continuação)

\begin{tabular}{|c|c|c|c|c|c|c|c|c|c|c|}
\hline & 11 & 12 & 13 & 14 & 15 & 16 & 17 & 18 & 19 & 20 \\
\hline 1 Agricultura & 0.02845 & 0.01595 & 0.00217 & 0.00694 & 000014 & 006079 & 0002603 & 0.43541 & 0.17801 & 0087722 \\
\hline 2. Mineração & 00011 & 000101 & 000013 & 000006 & 0.00011 & 0.0001 & 0.000302 & 0.00005 & 000004 & 0.0001 \\
\hline 3 Mirn Não-Met. & 0.00211 & 003125 & 0.02064 & 0.01583 & 0.00305 & 0.00037 & 0001167 & 000339 & 0.00017 & 0046107 \\
\hline 4. Metalurgia & 1628 & 001059 & 000867 & 0.02518 & 000948 & 000254 & 0.007168 & 001631 & 000168 & 0.069533 \\
\hline 5 Mecânica & 708 & 001410 & 0.00730 & 001024 & 001546 & 0.01600 & 0.006085 & 000919 & 0.01264 & 0019774 \\
\hline 6. Mat & 00107 & 0.00070 & 000052 & 0.00047 & 000080 & 000045 & 0.000671 & 000032 & 0.00026 & 0.000613 \\
\hline 7. Mat Tra & 209 & 000127 & 000085 & 000076 & 000090 & 000104 & 0.00177 & 0.00052 & 000041 & 1137 \\
\hline a/Mob & 000048 & 0.00107 & 0.00043 & 0.00062 & 000216 & 000081 & 0003213 & 0.00071 & 168 & 0.0042 \\
\hline 'apeläo & 000119 & 000310 & 001923 & 004718 & 0.01494 & 000386 & 0.011084 & 0.01133 & 129 & 0.008341 \\
\hline $10 \mathrm{Ed}$ & 0.00009 & 000020 & 000298 & 000291 & 0.00308 & 0.00045 & 0000805 & 093 & 10414 & 7785 \\
\hline 11. Bor & 0.26064 & 0.00027 & 000116 & 000034 & 000166 & 000130 & 0.01341 & 000004 & 003 & 0075 \\
\hline 12 Químico & 0.15245 & 016693 & 0.03309 & 0.14762 & 154 & 0.08381 & 0.028997 & 1202 & 110 & 55819 \\
\hline 13 Farmac. & 000027 & 000054 & 0.07869 & 000093 & 044 & $0.0003 \hat{1}$ & 0000174 & 0221 & 309 & 00741 \\
\hline 14 Perfumaria & 0.00018 & 0.00031 & 000020 & 0.00505 & 030 & 000046 & 0135 & 006 & 004 & 0.001801 \\
\hline 15. Plásticos & 000170 & 000309 & 001 & 4699 & 3516 & 000658 & 088 & 0.00723 & 133 & 0.010842 \\
\hline 16 Têxtil & 0.05359 & 0.00144 & 000 & 0.00146 & 586 & 7937 & 935 & 0.00912 & 0212 & 0000427 \\
\hline 17 Vest/Cour/Calç & 000168 & 000064 & 0.00065 & 000058 & 081 & 0.00250 & 0.066241 & 0.00054 & 000013 & 0000384 \\
\hline 18 Prod Aliment & 000065 & 0.01215 & 001010 & 0.09512 & 000146 & 0.00126 & 0030309 & 016842 & 0.00171 & 0076965 \\
\hline 19 Fumo & 000001 & 0.00002 & 0.00001 & 000001 & 0.00001 & 0.00001 & 0.000021 & 0.00001 & 018666 & 0000008 \\
\hline 20. Bebidas & 00001 & 0.00047 & 000012 & 000022 & 000018 & 0.00007 & 0.00007 & 0.00019 & 0013 & 64528 \\
\hline 21. Diversos & 000810 & 001005 & 000623 & 0.00405 & 0.00611 & 000696 & 0.011869 & 0.00352 & 380 & 0.006533 \\
\hline gua/Sanem & 000733 & 0.00819 & 0.00382 & 000302 & 001124 & 0.00915 & 0.003692 & 0.00627 & 0.00345 & 0009795 \\
\hline t Civil & & & & 0 & & & 0 & 0 & 0 & 0 \\
\hline $\mathrm{sp} / \mathrm{M}$ Com & 005292 & 0.06651 & 0.05202 & 0.07457 & 9506 & 0.04 & $0 \begin{array}{lll}0 & 034313\end{array}$ & 0.05543 & 0.02235 & 0045721 \\
\hline 25. Serviços & 0.07228 & 0.05158 & 0.17784 & 0.11086 & 0.08130 & 0.06085 & 0.08216 & 0.06503 & 0.08997 & 0.12231 \\
\hline
\end{tabular}


Tabela 1A (continuação)

\begin{tabular}{|c|c|c|c|c|c|}
\hline & 21 & 22 & 23 & 24 & 25 \\
\hline 1. Agricultura & 0.001703 & 0000963 & 0.000536 & 0.000156 & 0006065 \\
\hline 2 Mineração & 0009623 & 0000102 & 0.000074 & 0.00001 & 0000056 \\
\hline 3 Min Näo-Met. & 0030456 & 0003738 & 0123326 & 0000121 & 0001104 \\
\hline 4. Metalurgia & 0.113046 & 0001588 & 0.090774 & 0001345 & 0.00236 \\
\hline 5. Mecânica & 0048572 & 0016892 & 0010967 & 0.001378 & 0001772 \\
\hline 6 Mat Elétrico & 0.007098 & 0.022195 & 0.031372 & 0000415 & 0.002527 \\
\hline 7 Mat. Transp & 0002878 & 0000899 & 0001506 & 0.014956 & 0010196 \\
\hline 8. Madeira/Mob. & 0.010075 & 0000178 & 0039394 & 0.001081 & 0000838 \\
\hline 9.Papel/Papelão & 0013813 & 0001159 & 0000574 & 0006282 & 0.002939 \\
\hline 10 Edit /Graf & 0004395 & 0002471 & 0000354 & 0002873 & 0.01435 \\
\hline 11 Borracha & 0033817 & 0.001018 & 000136 & 0.007109 & 0004448 \\
\hline 12 Químico & 0029947 & 0022468 & 0028366 & 0105458 & 000967 \\
\hline 13 Farmacẽutica & 0000224 & 0000091 & 0000097 & 0000188 & 0.003749 \\
\hline 14 Perfumaria & 0000118 & 0.00004 & 0000042 & 0.000113 & 0000746 \\
\hline 15 Plásticos & 0015594 & 0.000486 & 0.020098 & 0.006822 & 0002003 \\
\hline 16 Têxtil & 0016177 & 0000229 & 0000651 & 0.002678 & 0005624 \\
\hline 17. Vest/Cour/Cal & 0002804 & 0.000223 & 0000696 & 0000223 & 0.001429 \\
\hline 18 Prod Aliment & 0002333 & 0000396 & 0000632 & 0.001335 & 0.015677 \\
\hline 19 Fumo & 0.000022 & 0000009 & 0000004 & 0.000002 & 0000006 \\
\hline 20 Bebidas & 0000078 & 0000032 & 0000063 & 0000083 & 0006033 \\
\hline 21 Diversos & 0018439 & 0006487 & 0003141 & 0.000622 & 0.002414 \\
\hline 22 En/Água/Sanem & 0002811 & 0.24729 & 0001147 & 0.006332 & 0008645 \\
\hline 23 Const Civil & & 0006627 & 0.050479 & 0004197 & 0025098 \\
\hline 24 Transp/M Com & 0070137 & 0023583 & 0.094534 & 0090557 & 0.062623 \\
\hline 25. Serviços & 0.068534 & 0.085488 & 0.034669 & 0.072213 & 0.147898 \\
\hline
\end{tabular}

Fonte: Versão agregada da matriz brasileira de coeficientes técnicos - 1980 Cálculos feito pelo autor a partir de dados do IBGE (IBGE, 1989).

\section{ABSTRACT}

\section{AN ANALYSIS OF THE ECONOMIC EFFECTS OF EXPORTS PROMOTION STRATEGIES}

The main purpose of this paper is to study the economic effects of different strategies for the promotion of exports, associated with export incentives of high and small added value goods Eight sectors of the Brazilian economy were considered in the study. Agriculture, Mining, Non-Metallic Minerals, Capital Goods (including mechanics, electric and transportation materials), Chemicals, and Processed Food Products Increases in export demand for these sectors were simulated through an aggregated version of the inputoutput Brazilian matrix. The estimated economic effects were the changes in output, imported inputs, and in employment. The findings of this study indicate that the processed food sector is likely to show the best economic performance 